\title{
5-Aminosalicylic acid enemas in the maintenance of remission in distal ulcerative colitis and proctitis
}

\author{
Lloyd R. SUTHERLAND, MD, FRCP(C), FranCOIS MARTIN, MD, FRCP(C)
}

ABSTRACT: A randomized clinical trial of the efficacy and safety of two different dosages of 5-aminosalicylic acid (5-ASA) enemas was carried out in 29 patients who had documented ulcerative colitis involving up to $50 \mathrm{~cm}$ of distal colon. All patients were in remission or had minimal disease activity (Disease Activity Index [DAI] less than 4) at the time of study entry. The two patient groups were similar in terms of age, sex ratio and disease activity. Further significant reduction in DAI occurred during the first three months of the study. Five patients (two in the $2 \mathrm{~g}$ group and three in the $4 \mathrm{~g}$ group) relapsed over the next six months. There were no significant differences in DAI of the two groups over the six month study period (ANOVA for repeated measures). Six patients dropped out of the study all of whom were in remission when last seen (mean follow-up 3.3 months). In this preliminary study, $2 \mathrm{~g}$ enemas were shown to be as effective as $4 \mathrm{~g}$ enemas in maintaining remission in patients with ulcerative colitis confined to the distal colon. Can J Gastroenterol 1987;1(1):3-6

Key Words: 5-Aminosalicylic acid (5-ASA), Clinical trial, Enemas, Ulcerative Colitis

U LCERATIVE COLITIS IS A CHRONIC relapsing inflammatory condition characterized by mucosal inflammation and limited to the large intestine. Past therapy has included corticosteroids, administered both topically and systemically, and sulfasalazine, a novel combination of a sulfa moiety and 5aminosalicylic acid (5-ASA). Recent studies have demonstrated that $5-\mathrm{ASA}$ is the active therapeutic agent in sulfasalazine (1) and that other delivery systems can provide sufficient 5-ASA to the colon (2). New oral and topical formula-

Departments of Gastroenterology, University of Calgary (Foothills Provincial Hospital) and University of Montreal

Reprints: Dr Lloyd R. Sutherland, Room 1414,3330 Hospital Drive NW, Calgary, Alberta $\mathrm{T} 2 \mathrm{~N} 4 \mathrm{~N} 1$

Received June 4, 1987. Accepted July 16, 1987

tions of 5-ASA currently are being assessed. The authors have previously reported experience with one 5-ASA enema preparation in the treatment of acute ulcerative colitis confined to the distal colon (3). Patients who completed that study were offered an opportunity to participate in the maintenance study reported here.

The purpose of the study was to evaluate the efficacy and safety of a 5-ASA enema preparation (Rowasa; ReidRowell Inc) in the maintenance of remission in patients with ulcerative colitis confined to the distal large intestine and to determine if there were significant differences between $2 \mathrm{~g}$ and $4 \mathrm{~g}$ enemas in maintaining remission.

\section{METHODS}

Two centres participated in the study, a six month, randomized double-blind, two dose design. The protocol was reviewed by the individual ethics committees or Institutional Review Boards of the participating institutions. Written informed consent was obtained from each patient before the study. 


\section{TABLE 1}

Disease Activity Index (DAI): Qualitative rating scale with four subscales

\begin{tabular}{lc}
\hline Symptom & Score \\
\hline Stool frequency & \\
Normal & 0 \\
$1-2$ Stools/day $>$ normal & 1 \\
$3-4$ Stools/day $>$ normal & 2 \\
$>4$ Stools/day $>$ normal & 3 \\
Rectal bleeding & \\
None & \\
Streaks of blood & 0 \\
Obvious blood & 1 \\
Mostly blood & 2 \\
Mucosal appearance & 3 \\
Normal & \\
Mild friability & 0 \\
Moderate friability & 1 \\
Exudation, spontaneous bleeding & 3 \\
Physician rating of disease activity & 3 \\
Normal & \\
Mild & \\
Moderate & \\
Severe & \\
Maximum &
\end{tabular}

The study population comprised outpatients, aged 18 years or older who had ulcerative colitis involving a minimum of $5 \mathrm{~cm}$ to a maximum of $50 \mathrm{~cm}$ of colon continuously from the anus, confirmed by sigmoidoscopy with biopsies taken from an area of active disease and above the disease boundary. Before admission to the study, patients had participated in a trial of 5-ASA enema versus placebo and had achieved a significant improvement in their disease activity or were in remission. Patients had a maximum score of 4 on a 12 point Disease Activity Index (DAI) (Table 1). History of salicylate allergy, disease involving more than $50 \mathrm{~cm}$ of disease, previous bowel resection or clinically significant hepatic or renal disease were grounds for exclusion. Pregnant women were also excluded. No rectally administered steroid medications were allowed.

Random assignment to either $2 \mathrm{~g}$ or $4 \mathrm{~g}$ 5-ASA enemas $(60 \mathrm{~mL}$ suspension per disposable unit of use retention enema) was accomplished by the assignment of patient study numbers using a table of random numbers. Double-blind medication was pre-packaged to insure an equal and random assignment within each centre. Patients were not stratified as to duration or extent of disease.
Concurrent medications: Oral steroids could be continued if the patient had taken them for more than four weeks and if the dose had stabilized at less than $30 \mathrm{mg}$ of prednisone or equivalent. Oral sulfasalazine was allowed if the medication had been used regularly for more than four weeks prior to entrance. In either case, the dose of steroid or sulfasalazine remained constant for the first month of the study and then most patients had their steroids or sulfasalazine discontinued.

Disease Activity Index: The DAI (Table 1) has been used in the past (4) and it provides an objective criteria for assessment of drug efficacy. It assesses four variables: stool frequency; rectal bleeding; sigmoidoscopic appearance of mucosa; and physician's assessment of disease severity. Each variable has a range of values for severity with 0 representing no abnormality and 3 representing the most severe. Because the variables have equal weighting, the DAI can range from 0 to 12 . The DAI was calculated at the end of three months and six months of the study and represented an integration of data collected by the patient on his or her diary card for the preceding week.

Procedures: On entry to the study a complete history, physical examination and flexible sigmoidoscopy were done. Biopsies were obtained to document the remission with previous biopsies from the acute study available for comparison (to be reported at a later date). Hematologic (complete blood count and sedimentation rate), biochemical parameters (SMA-12 or equivalent) and urinalysis (with microscopic examination) were assessed along with stool culture to exclude infectious colitis. The DAI was calculated.

Patients were given a one month supply of enemas which contained either $2 \mathrm{~g}$ or $4 \mathrm{~g}$ of 5 -ASA in a $60 \mathrm{~mL}$ suspension. They were instructed to use one enema daily at bedtime. Diary cards were given to record their symptoms (stool frequency, bleeding, cramping) on a daily basis. They were also asked to record any other medications taken, other symptoms or possible side effects and the number of hours that the enema was retained. Telephone contact was made with the patients to assess patient symptoms and to encourage compliance.

At the end of each month the patients returned to obtain a further month's supply of medication. The stool frequency and presence of blood in the stool were ascertained. For some patients an optional sigmoidoscopy was carried out. At three months, repeat sigmoidoscopy was done on all available patients. The DAI was calculated. If there was deterioration (DAI greater than 4) the patient was considered to have relapsed and was withdrawn from the study.

At the conclusion of the six-month study, flexible sigmoidoscopy with biopsy was repeated. Physical examination with hematologic and biochemical assessment including urinalysis was carried out and the DAI calculated.

Statistical analysis was carried out using a multipurpose statistical package, BMDP (5). Patient group characteristics were assessed by $t$ testing. The relapse rate was tested for significance by $\chi^{2}$ analysis. ANOVA for repeated measures was used to determine if there were significant changes between the $2 \mathrm{~g}$ and $4 \mathrm{~g}$ enema groups and to assess changes in DAI over time.

\section{TABLE 2}

\section{Patient characteristics}

\begin{tabular}{lcc}
\hline & 2 g 5-ASA & 4 g 5-ASA \\
\hline Number of patients & 15 & 14 \\
Sex ratio (male:female) & $1: 2$ & $1: 1$ \\
Age (mean)(years) & 39.0 & 37.2 \\
Disease boundary (cm) & 25.0 & 36.9 \\
Concurrent oral steroids & 1 & 4 \\
Concurrent sulfasalazine & 6 & 4 \\
Entry DAl & 1.80 & 2.64 \\
Dropouts & 4 & 2 \\
\hline
\end{tabular}

Patients: Twenty-nine patients entered the trial (Table 2), 15 received the $2 \mathrm{~g}$ enema suspension and 14 the $4 \mathrm{~g}$ preparation. Both groups were similar in composition regarding sex, age and concurrent medication. Patients receiving $4 \mathrm{~g}$ 5-ASA had more extensive disease but the difference was not significant $(\mathrm{P}=0.06)$

Six patients (four on $2 \mathrm{~g}$ enemas and two on $4 \mathrm{~g}$ enemas) dropped out during the study (Table 3). Mean follow-up for 
TABLE 3

Response to $2 \mathrm{~g}$ or $4 \mathrm{~g}$ 5-ASA enemas over time

\begin{tabular}{lcc}
\hline & $2 \mathrm{~g}$ & $4 \mathrm{~g}$ \\
(number of patients)
\end{tabular}

No significant difference between $2 \mathrm{~g}$ and $4 \mathrm{~g}$ enemas

TABLE 4

DAl scores before and after treatment with $2 \mathrm{~g}$ or $4 \mathrm{~g}$ 5-ASA enemas

\begin{tabular}{lcc}
\hline Time & $\begin{array}{c}2 \mathrm{~g} \\
\text { (number of patients) }\end{array}$ \\
\hline Entry & $1.80(15)$ & $2.64(14)$ \\
Three months & $0.62(13)$ & $0.85(13)$ \\
Six months & $0.60(10)$ & $1.11(9)$ \\
\hline
\end{tabular}

Includes those in remission and relapse: $P<0.001$ between entry and three months; No significant difference between three and six months or between $2 \mathrm{~g}$ and $4 \mathrm{~g}$ enemas

these was the same for both groups ( 3.3 months). All were in remission when last assessed.

\section{RESULTS}

Maintenance of remission was assessed by examination of changes in the DAI. Relapse was defined by a DAI greater than 4. Five patients (two on $2 \mathrm{~g}$ per day and three on $4 \mathrm{~g}$ per day ) relapsed during the study period. Relapse rates did not differ significantly (Table 3). The overall relapse rate at three months was $15 \%$ and by six months it had risen to $22 \%$ (excluding "dropouts"). Response to treatment was not influenced by concurrent treatment with either steroids or sulfasalazine.

Significant declines in DAI were demonstrated for both groups during the first three months of therapy (Table 4). There were no significant changes in DAI during the last three months of the study. ANOVA for repeated measures did not demonstrate significant differences between the two treatment groups.

Side effects: Patients were asked to record on their diary cards any unusual occurrences during the study period. Side effects were few and insignificant. No clinically significant changes were observed in hematology, blood chemistry or urinalysis.

\section{DISCUSSION}

The treatment of acute ulcerative colitis is often challenging, and the high recurrence rate associated with the condition has led to the concept of maintenance therapy to obtain a longer interval between relapse. Truelove (6) has reported that without maintenance therapy the relapse rate in one year will approach $80 \%$. Misiewicz and collegues (7) first demonstrated that sulfasalazine compared to placebo was effective in maintaining remission in patients with ulcerative colitis. Patients receiving placebo had a fourfold increase in the relapse rate compared to patients on sulfasalazine. The recommended dose of sulfasalazine is $2 \mathrm{~g}$ per day, as higher doses are associated with more side effects and are not accompanied by an increased protection from relapse (8).

There remains some controversy as to the length of time therapy should be given but some authorities recommend indefinite therapy. Others suggest that taking $3 \mathrm{~g}$ per day of sulfasalazine as soon as any disease symptoms occur is as effective as taking $2 \mathrm{~g}$ daily in prevention of significant disease relapse (9), 5-ASA tablets are as effective as sulfasalazine in maintaining remission in patients with quiescent disease (10).

Spencer and colleagues (11) have also demonstrated that high dose corticosteroid therapy could maintain remission but at the cost of significant side effects. Alternate day steroids can provide some protection against relapse but at a cost of increased risk from long term steroid therapy (12).

This is one of the first studies of the effectiveness of 5-ASA enemas in maintaining disease remission among patients who had previously responded to the enema when their disease was active. Only $22 \%$ of patients (excluding "dropouts") taking 5-ASA enemas had a relapse of their disease. The higher dose enemas were not superior to the $2 \mathrm{~g}$ enemas. Biddle (13) has shown that as little as $1 \mathrm{~g}$ of 5-ASA is more effective than placebo in maintaining remission in patients with left sided ulcerative colitis.
Small clinical trials must always be concerned with the possibility of a type II error, ie, concluding that there is no difference between the two treatments when in fact there is a difference. To eliminate that possibility a sample size of 250 patients would be required (alpha $=$ 0.05 , beta $=0.20$ ).

Although the present drop out rate was relatively high, the majority of "dropouts" were in remission when they left the study. As most patients had already used nightly enemas for six weeks prior to study entrance, it was not surprising that some wished to discontinue the practice after two or three months of additional therapy.

Some patients stated that sulfasalazine had been ineffective in maintaining remission in the past. Whether 5-ASA enemas are superior to 5-ASA tablets or sulfasalazine in maintaining remission in patients with left sided colitis remains to be answered.

Although therapeutic trials of a poorly absorbed steroid enema $(14,15)$ have shown efficacy for patients with ulcerative colitis, the present authors are not aware of any maintenance studies using these formulations. Therapy using conventional hydrocortisone enemas has not been shown to be more effective than placebo in prolonging remission (16).

Ginsberg and others (17) have demonstrated that 4-aminosalicylic acid (4-ASA) enemas are also more effective than placebo in treatment of left sided colonic disease. Whether or not there are significant advantages in using 4-ASA preparations compared to 5-ASA compounds is not clear.

In conclusion, it appears that 5-ASA enemas have a role to play in maintenance therapy of patients with ulcerative colitis confined to the distal colon. Based on experience in this preliminary trial, therapy with a $2 \mathrm{~g}$ enema may suffice to maintain remission.

ACKNOWLEDGEMENTS: The authors acknowledge the cooperation and support of the following co-investigators: Drs M Gagnon, H Hershfield, J Langevin, K MacCannell, L Price, EShaffer. This study was sponsored by Reid-Rowell Inc, Baudette, Minnesota, and Interfalk Canada, Beloil, Quebec. 


\section{REFERENCES}

1. Azad Khan AK, Howes DT, Truelove SC. An experiment to determine the active moiety of sulphasalazine. Lancet 1977;ii:892-5.

2. Hawkey CJ. Salicylates for the sulfa-sensitive patient with ulcerative colitis? Gastroenterology 1986;90:1083-5.

3. Sutherland LR, Martin F. 5-aminosalicylic acid (5-ASA) enemas in the treatment of distal ulcerative colitis and proctitis (A Canadian Study). Dig Dis Sci 1987. (In press)

4. Sutherland LR, Martin F, Greer S, et al. 5-aminosalicylic acid (5-ASA) enema in the treatment of distal ulcerative colitis, proctosigmoiditis, and proctitis. Gastroenterology 1987;92:1894-98.

5. Dixon WJ (ed). BMDP Statistical Software. Berkeley: University of California Press, 1985.

6. Truelove SC. Treatment of ulcerative colitis with local hydrocortisone hemisuccinate sodium: a report of a controlled therapeutic trial. Br Med 1958;2:1072-7.

7. Misiewicz JJ, Lennard-Jones JE, Connell
AM, et al. Controlled trial of sulphasalazine in maintenance therapy for ulcerative colitis. Lancet 1965;i:185-8

8. Dissanayake AS, Truelove SC. A controlled therapeutic trial of long-term maintenance treatment of ulcerative colitis with sulphasalazine. Gut 1973; 14:923-6.

9. Dickinson RJ, King A, Wight DGD, Hunter JO, Neale G. Is continuous sulfasalazine necessary in the management of patients with ulcerative colitis? Dis Colon Rectum 1985;28:929-30.

10. Riley SA, Mani V, Goodman MJ, Turnberg LA. A comparison of delayed-release 5-aminosalicylic acid and sulphasalazine as maintenance treatment of ulcerative colitis. Gastroenterology 1987;92:1596. (abst)

11. Spencer JA, Kirsner JB, Milynaryk P, Reed PI, Palmer WL. Immediate and prolonged therapeutic effects of corticotrophin and adrenal steroids in ulcerative colitis. Gastroenterology 1962;42:113-28.

12. Powell-Tuck J, Bown RL, Chambers TJ,
Lennard-Jones JE. A controlled trial of alternate day prednisolone as a maintenance treatment for ulcerative colitis in remission. Digestion 1981;22:263-70.

13. Biddle WL, Greenburger NJ, Swan JT, McPhee MS, Miner PB. 5-aminosalicylic acid enemas (5-ASA): Effective agent in maintaining remission in left-sided ulcerative colitis. Gastroenterology 1987;92:1316. (abst)

14. McIntyre PB, Macrae FA, Berghouse L, English J, Lennard-Jones JE. Therapeutic benefits from a poorly absorbed prednisolone enema in distal colitis. Gut $1985 ; 26: 822-4$

15. Friedman G. Treatment of refractory proctosigmoiditis and left-sided colitis with a rectally-instilled non-glucocorticoid, non-mineral corticoid steroid. Gastroenterology 1985;88:1388. (abst)

16. Ginsberg AL, Beck LS, McIntosh TM. Nochomovitz LE. Placebo controlled trial of 4-aminosalicylic acid enemas in left sided ulcerative colitis. Gastroenterology 1987;92:1406. (abst) 


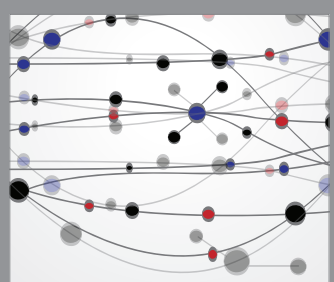

The Scientific World Journal
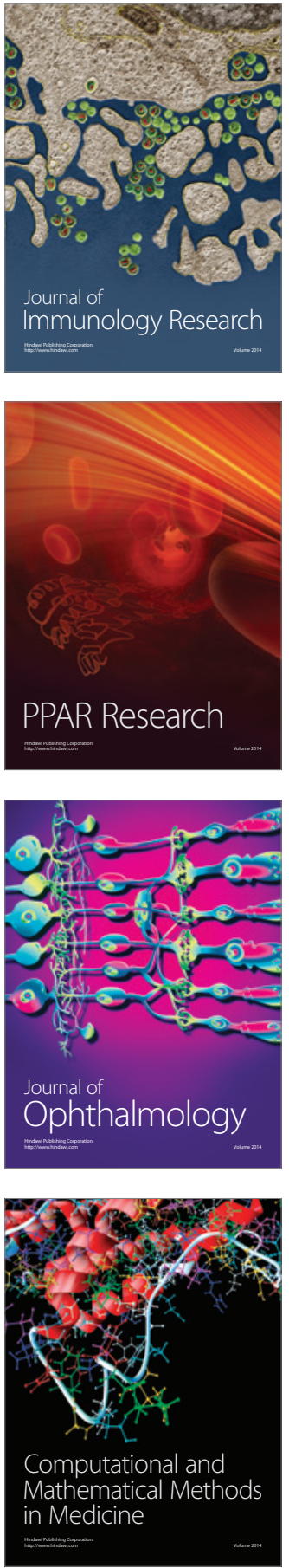

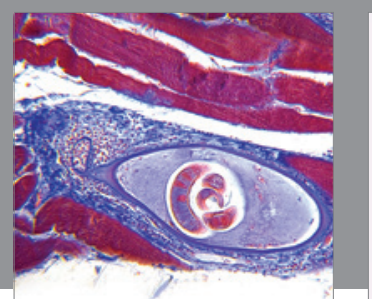

Gastroenterology Research and Practice

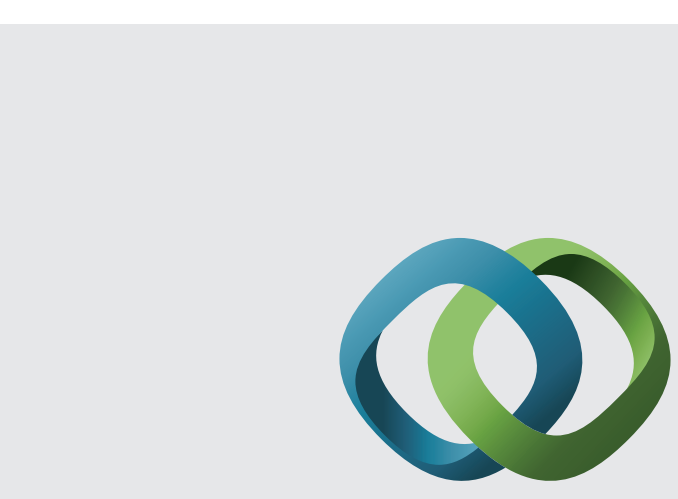

\section{Hindawi}

Submit your manuscripts at

http://www.hindawi.com
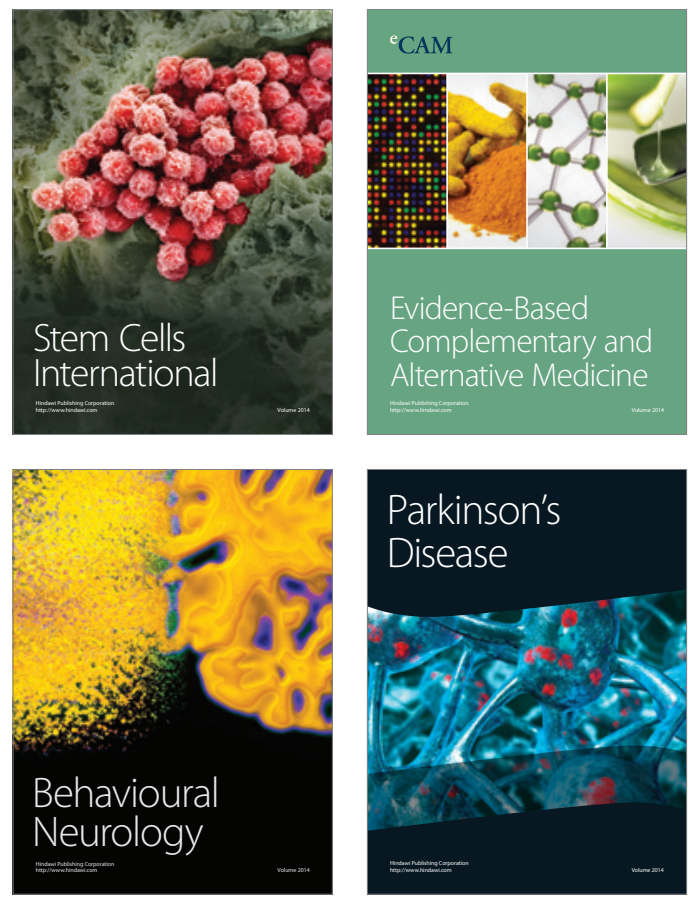
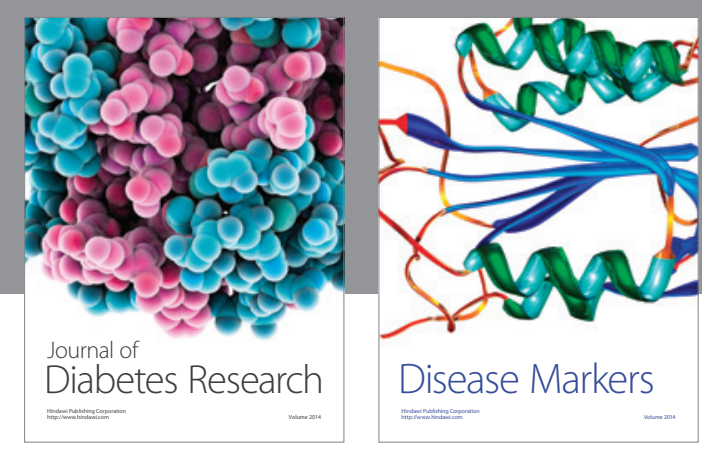

Disease Markers
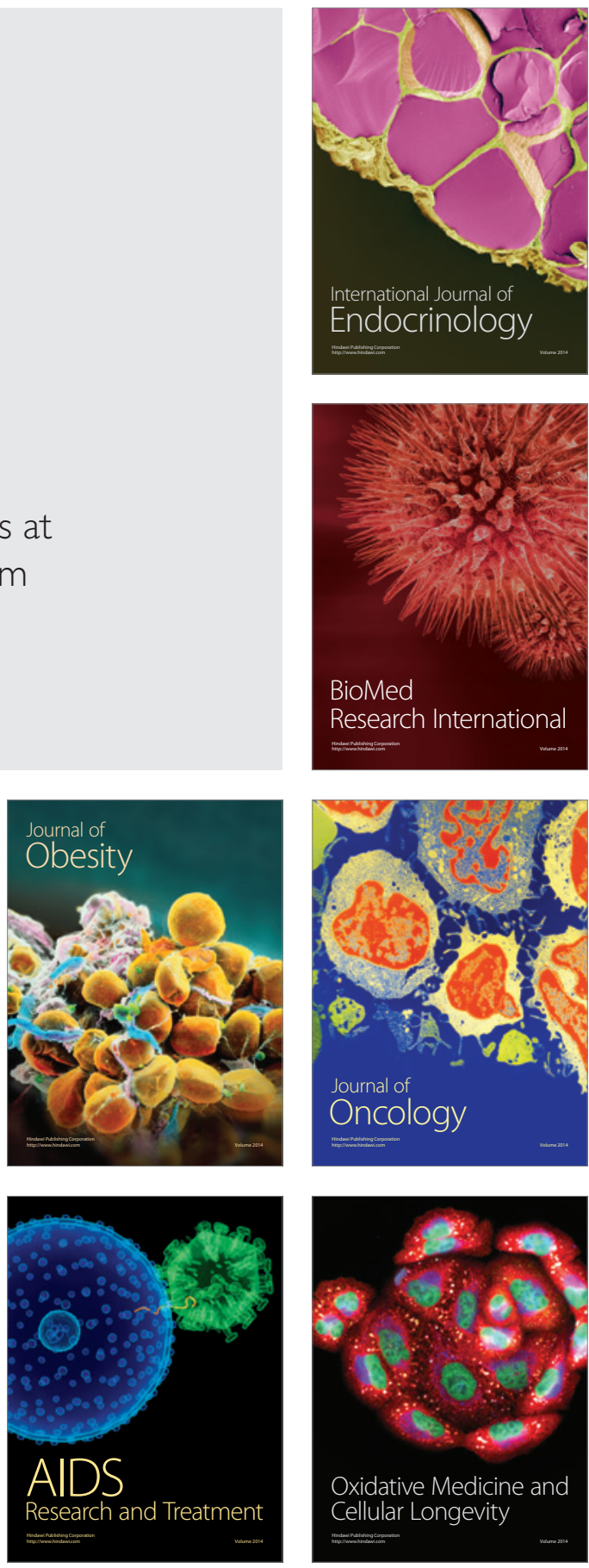